\title{
Correction to: Butyrophilin-like 9 expression is associated with outcome in lung adenocarcinoma
}

Weishuang $\mathrm{Ma}^{1,2+}$, Jiaming Liang ${ }^{3 \dagger}$, Junjian $\mathrm{Mo}^{1+}$, Siyuan Zhang ${ }^{1 \dagger}$, Ningdong $\mathrm{Hu}^{4}$, Dongbo Tian ${ }^{1 *}$ and Zisheng Chen $^{1 *}$

\section{Correction to: BMC Cancer 21, 1096 (2021) \\ https://doi.org/10.1186/s12885-021-08790-9}

Following publication of the original article [1], the authors identified an error in Fig. 2. The gene BTN3A1 has Chinese text characters, and BTN3A2, BTN3A3, BTNL2, BTNL3, BTNL8, BTNL9, BTNL10, and SKINTL are not marked.

The corrected Fig. 2 is given below and the original article [1] has been corrected.

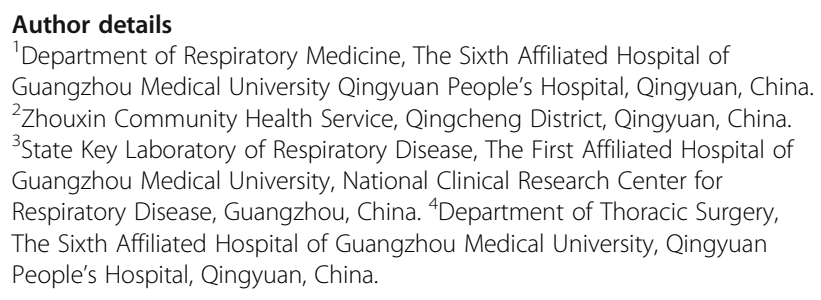

Published online: 26 October 2021

\section{Reference}

1. Ma W, Liang J, Mo J, et al. Butyrophilin-like 9 expression is associated with outcome in lung adenocarcinoma. BMC Cancer. 2021;21:1096. https://doi. org/10.1186/s12885-021-08790-9.

The original article can be found online at https://doi.org/10.1186/s12885021-08790-9.

*Correspondence: 2682105044@qq.com; 502463784@qq.com

+Weishuang Ma, Jiaming Liang, Junjian Mo and Siyuan Zhang contributed equally to this work.

${ }^{1}$ Department of Respiratory Medicine, The Sixth Affiliated Hospital of Guangzhou Medical University Qingyuan People's Hospital, Qingyuan, China

Full list of author information is available at the end of the article

(c) The Author(s). 2021 Open Access This article is licensed under a Creative Commons Attribution 4.0 International License, which permits use, sharing, adaptation, distribution and reproduction in any medium or format, as long as you give appropriate credit to the original author(s) and the source, provide a link to the Creative Commons licence, and indicate if changes were made. The images or other third party material in this article are included in the article's Creative Commons licence, unless indicated otherwise in a credit line to the material. If material is not included in the article's Creative Commons licence and your intended use is not permitted by statutory regulation or exceeds the permitted use, you will need to obtain permission directly from the copyright holder. To view a copy of this licence, visit http://creativecommons.org/licenses/by/4.0/. The Creative Commons Public Domain Dedication waiver (http://creativecommons.org/publicdomain/zero/1.0/) applies to the data made available in this article, unless otherwise stated in a credit line to the data. 


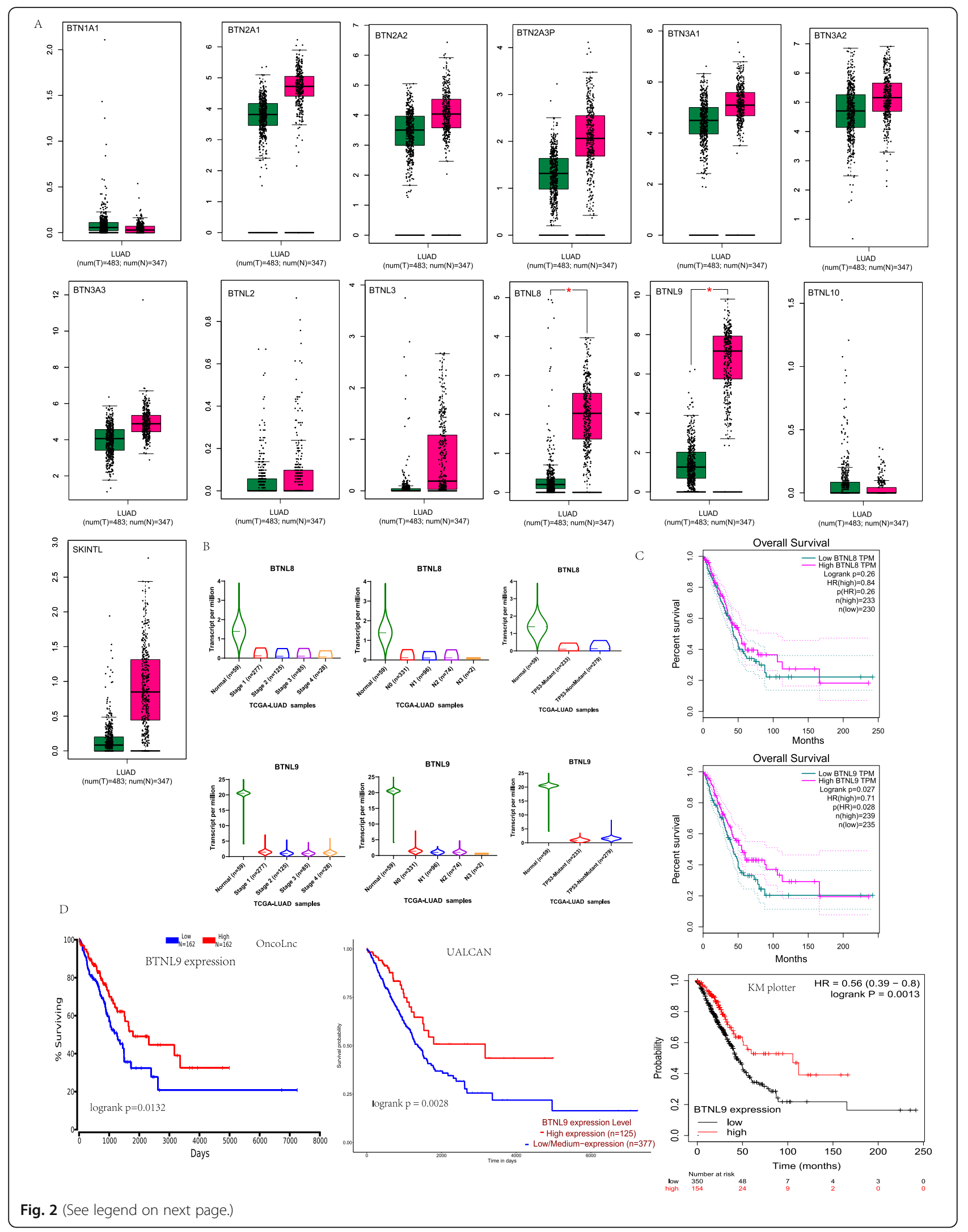


(See figure on previous page.)

Fig. 2 BTNL9 Expression and prognosis in LUAD. A BTNs expression panel in LUAD tissues compared with adjacent tissues in GEPIA database. B Correlation between BTNL8 and BTNL9 expression and LUAD clinical stages, N stage, and p53 mutation in the UALCAN database (BTNL8 expression compared with LUAD clinical stages (Normal-vs-Stage1, $P=1.01 \mathrm{E}-04$; Normal-vs-Stage2, $P=7.08 \mathrm{E}-03$; Normal-vs-Stage3, $P=1.36 \mathrm{E}-04$; Normal-vs-Stage4, $P=1.78 \mathrm{E}-08$ ), N stage (Normalvs-NO, $P=6.56 \mathrm{E}-04$; Normal-vs-N1, $P=8.27 \mathrm{E}-10$; Normal-vs-N2, $P=5.96 \mathrm{E}-04$; Normal-vs-N3, $P=$ 1.97E-10; NO-vs-N1, $P=3.27 \mathrm{E}-03$; N0-vs-N3, $P=6.79 \mathrm{E}-04$ ), and $p 53$ status (Normal-vs-T P53-Mutant, $P=1.27 \mathrm{E}-06$; Normal-vs-T P53-NonMutant, $P=$ 1.80E-03). BTNL9 expression comparison with LUAD clinical stages (Normal-vsStage1, $P=1.21 \mathrm{E}-12$; Normal-vs-Stage2, $P=3.60 \mathrm{E}-13$; Normal-vsStage3, $P=2.40 \mathrm{E}-12$; Normal-vs-Stage4, $P=2.25 \mathrm{E}-12$ ), N stage (Normal-vs-NO, $P=1.08 \mathrm{E}-12 ;$ Normal-vs-N1, $P=1.85 \mathrm{E}-12 ;$ Normal-vs-N2, $P=1.02 \mathrm{E}-12$; Normal-vs-N3, $P=1.67 \mathrm{E}-12$; NO-vs-N1, $P=1.02 \mathrm{E}-03 ;$ N2-vs-N3, $P=3.01 \mathrm{E}-02$ ), and P53 status (Normal-vs-T P53-Mutant, $P=1.85 \mathrm{E}-12$; Normal-vs-T P53NonMutant, $P=4.10 \mathrm{E}-12$; T P53-Mutant-vs-T P53-NonMutant, $P=1.77 \mathrm{E}-04)$ ). C Correlation between BTNL8 and BTNL9 expression with overall survival of LUAD using GEPIA database. D Correlation between BTNL9 expression and LUAD overall survival using OncoLnc, UALCAN, and KM plotter databases. ${ }^{*}:$-value $<0.05 ;^{* *}:$-value $<0.01 ;^{* * *}:$-value $<0.001$ 